\title{
Some Highlights and Issues to Consider
}

Can. J. Neurol. Sci. 2005; 32: 1-3

The past year had much to offer and hopefully inspire CJNS readers. It has been a privilege for me to see the journal evolve in several positive directions. In November's issue, I highlighted the results of our CJNS Editorial Board meeting held last June. In this note, I would like to begin with several acknowledgements. First, thank you to our referees for their dedicated appraisals of manuscripts. Their names are listed in this issue (in bold for five or more reviews). Thank you also to members of our Editorial Board who are involved in reviewing most manuscripts that are submitted and to our Associate Editors for their work. Finally, many thanks to the relentless and superb efforts of the CJNS office staff, Myrna Gowing, Sue Impey and our Managing Director, Sally Gregg. The selection of the beautiful 30th anniversary campaign logo is one example of the creativity exhibited by this group.

There are important issues to discuss concerning Neuroscience research in Canada. On November 26 and 27, 2004, the Institute of Neurosciences, Mental Health and Addiction (INMHA@cihr-irsc.gc.ca) of CIHR (Canadian Institutes of Health Research), held its annual meeting in Ottawa. This year, the themes of the meeting were Epilepsy, Vision Health and Schizophrenia. In conjunction with the meeting, the Honourable Robert G. Thibault, Parliamentary Secretary to the Minister of Health, on behalf of the Honourable Ujjal Dosanjh, Minister of Health and Dr. Rémi Quirion, Scientific Director of the Institute of Neurosciences, Mental Health and Addiction (INMHA), presented the Brain Star of the Year Award to Jeffrey Coull from McGill. Jeffrey Coull was recognized for the paper, "Transsynaptic shift in anion gradient in spinal lamina I neurons as a mechanism of neuropathic pain (Nature 424: 938-942)". "The excellence of Jeff's research and its interdisciplinary nature has the potential to positively impact the health of many Canadians," says Dr. Rémi Quirion. "The investments being made by INMHA in today's young researchers will help to put Canada at the forefront of brain research in the world." Brain Star awards are made regularly (biweekly) by INMHA to trainees in neurosciences, mental health or addiction research. The awards recognize the work of graduate students, postdoctoral fellows and residents. In this issue of CJNS, we are also pleased to publish a review paper prepared by Min Zhou after last year's INMHA meeting entitled, "Cellular and synaptic insights into physiological and pathological pain”. Dr. Zhou was awarded the EJLB-CIHR Michael Smith Chair in Neurosciences and Mental Health for his work.
Mr. Thibault also announced the recipients of the NeuroScience Canada Brain Repair Program, a competitive application for projects on innovative strategies for neurological treatment. NeuroScience Canada (www.neurosciencecanada.ca), managed by President Ms. Inez Jabalpurwala in partnership with INMHA, was founded in 1998 to address the burden of neurological disease on Canadians. The group provides funds for research into the mechanisms that protect and repair the brain and nervous system. Following rigorous peer review conducted over an eight-month period, the recipients were:

1. Dr. Freda Miller, Hospital for Sick Children, Toronto and colleagues for their work on Novel approaches to central nervous system white matter repair.

2. Dr. Michael W. Salter, Hospital for Sick Children, Toronto and colleagues for their work on Transforming research on chronic pain in Canada.

3. Dr. Yu Tian Wang, University of British Columbia/Vancouver Coastal Health Research Institute, Brain Research Centre at UBC Hospital, Vancouver and colleagues for their work on Novel therapeutic strategies to repair brain abnormalities in psychiatric disorders.

Despite all of this very positive news however, and considerable lobbying, overall research funding in Canada is at an uncertain juncture. Despite some increases, CIHR has not yet been pegged to the kind of overall funding level that would put Canadian researchers in a world class playing field. For independent investigators the competition for new and renewal operating grants is very intense, with only grants rated at or above the excellent (4.0) level now being funded. Even more discouraging is the possibility that CIHR may be faced with new planned cutbacks despite the presence of a federal budget surplus. If you deplore such steps backward, it is critical you write your local MP and raise this issue as soon as possible. The spinoffs that could emerge from a properly funded Canadian neuroscience research infrastructure and team are enormous.

The Canadian Journal of Neurological Sciences begins 2005 with another superb collection of papers. Two articles, both highly rated by our referees, address issues of multiple sclerosis epidemiology in Newfoundland. Colleagues from the University of Western Ontario have provided us with an outstanding neuropathological conference. For readers like myself, who have been addicted to CPCs once published weekly (and now disappearing) from highly cited journals south of Canada, this one may fill the niche. Please send us more. We are also fortunate 
to publish two Neuroimaging Highlights in this issue and I wish to thank our Highlight editors, Dr. Richard Farb from Toronto and Mark Hudon from Calgary, for their evaluations. The criteria for publishing the Highlights continue to be a combination of cutting edge Neuroimaging with unique and important clinical features. Unlike previous years, we have had no shortage of Highlight submissions and have accepted many. There is a concern that too many such pieces can diminish our impact factor but I believe their educational value outweighs this concern and how we present them reflects this emphasis (not as page fillers). Please continue to send them.

My challenge to the readership in 2005 is for another substantial increase in submissions. Send us your high impact work first. It will be disseminated rapidly and without barriers as free full text worldwide.

My sincere wishes to all for a successful 2005.

Douglas Zochodne

[Disclosures for 2004: DW Zochodne collaborated in research work with SKK, Japan and Aegera, Canada. Honoraria and travel expenses were paid for extramural lectures at the Japan Diabetes Society, Tokyo, Japan (ONO), Hirosaki University Japan (ONO), Diabetic neuropathy satellite symposium, St. Malo, France (Viatris), and Grand rounds, Division of Neurology, Winnipeg, Canada (Bayer)].

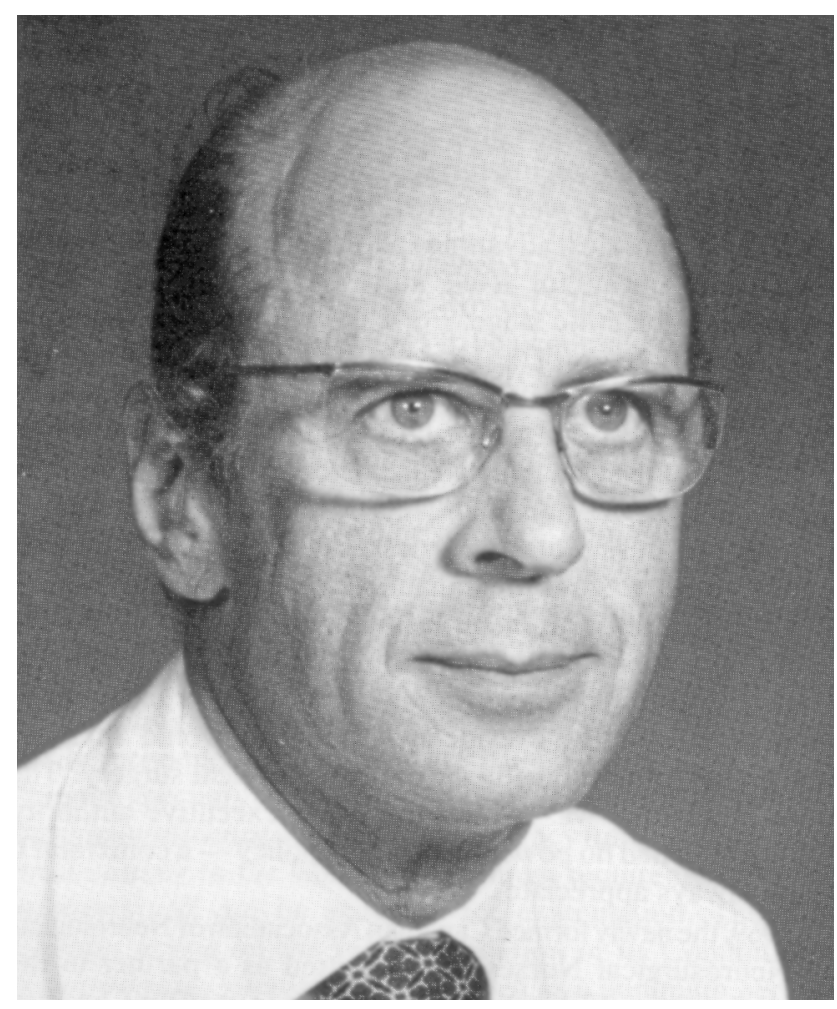

Dr. Robert Ross, founding editor of CJNS, attended and addressed the 39th Canadian Congress of Neurological Sciences in June in Calgary. Thirty years ago Dr. Ross was alone among peers in creating and fostering a Canadian clinical neurosciences journal. Today, CJNS is now owned and operated by the four constituent societies of the Canadian Congress of Neurological Sciences. 


\section{Thank you to our Reviewers}

We are indebted to the expert referees who have reviewed submission to the Canadian Journal of Neurological Sciences in 2004 (names in bold reviewed five or more papers). Their thoughtfulness and expertise has served our journal well.

\begin{tabular}{|c|c|c|c|c|}
\hline Coleen Adams & Elizabeth Donner & Christopher Honey & Jeffrey Minuk & Brian Silver \\
\hline Eric Ahlskog & Joseph Dooley & Robin Hsiung & William Morrish & Roger Simon \\
\hline Lee-Cyn Ang & James Drake & $\mathrm{Bin} \mathrm{Hu}$ & S. Terence Myles* & Kenneth Smith \\
\hline Nigel Ashworth & Neil Duggal & Mark Hudon & Avindra Nath & J. David Spence \\
\hline Peter Bailey & Pierre Duquette & R. John Hurlbert & Avindra Nath & Ian Spreadbury \\
\hline Jaideep Bains & Felix Durity & Alan Jackson* & Michael Nicolle & Paul Steinbok* \\
\hline Brenda Banwell & John Edmeads & Claudia Jacova & John Noseworthy & B.J. Stern \\
\hline Philip Barber & Chris Ekong & Jack Jhamandas & Paul O'Connor & A. Jonathan \\
\hline Ian Beauprie & Michael Eliasziw & Jack Jhamandas & Brian O'Neill & Oksana Suchowersky* \\
\hline Werner Becker & Derek Emery & Jack Jhamandas & Norm O'Rourke & Mecheri Sundaram \\
\hline Eric Belanger & David Fairholm & Mandar Jog & Isamu Ozaki & Jeanne Teitelbaum \\
\hline Vadim Beletsky & Richard Farb & Edward Johnson & Ian Parney & James Toole \\
\hline Robert Bell & Paolo Federico & Janine Johnston & Andrew Parrent & Cory Toth \\
\hline Brien Benoit & Howard Feldman & Stephen Karlik & David Patry & Brian Toyota \\
\hline Francois Bernier & Paul Fernyhough & Anthony Kaufmann & Sydney Peerless & Kenneth Tyler \\
\hline Mark Bernstein & Stephen Field & Robert Kearney & David Pelz & Hillar Vellend \\
\hline Virender Bhan & J. Max Findlay* & Daniel Keene* & James Perry & Harry Vinters \\
\hline Jose Biller & Hillel Finestone & Ralph Kern & Neelan Pillay & Carla Wallace \\
\hline Jeff Blackmer & Ian Fleetwood* & Andrew Kertesz & Milos Popovic & Christopher Wallace \\
\hline Warren Blume & David Fortin & Andrew Kirk & Christopher Power & Timothy Watson \\
\hline Christian Bocti & Daryl Fourney & Zelma Kiss & William Pryse-Phillips & Stephen Waxman \\
\hline Daniel Boghen & Allan Fox & Douglas Kondziolka* & Allan Purdy & Donald Weaver \\
\hline Julien Bogousslavsky & Richard Fox & Scott Kraft & David Ramsay* & Theodore Wein \\
\hline Charles Bolton & Jeffrey Frank & Andre Krassioukov & Alexander Razumovsky & Nic Weir \\
\hline Jonathan Brotchie & Mark Freedman & Jerry Krcek & Gary Redekop & Shelly Weiss \\
\hline Russell Brown & James Frey & Anne-Louise LaFontaine & George Rice & Lisa Welikovitch \\
\hline Robert Brownstone & Sarah Furtado & David Lacomis & Peter M. Richardson* & Richard Wennberg \\
\hline Donald Brunet & Alexis Gagnon & Anthony Lang & Lawrence Richer & B. Matt Wheatley \\
\hline Alastair Buchan & Marek Gawel & John Latter & Richard Riopelle & Brian Wheelock \\
\hline Andrew Bulloch & Angela Genge & Mark Lawden & Ted Roberts & William Whitelaw \\
\hline Ray Buncic & David George & Andrew Leung & Gordon Robinson & Samuel Wiebe* \\
\hline Gregory Cairncross* & Kevin Gordon & Dan Levy & Guy Rouleau* & David Wiebers \\
\hline Peter Camfield & Francois Grand'Maison & M. David Low & Jeffrey Rumbaugh & Robert Willinsky \\
\hline Richard Camicioli & Ian Grant & David MacDonald & James Rutka & Richard Wilson \\
\hline Steven Casha & David Grimes & Jean Mah & Abbas Sadikot & Elaine Wirrell \\
\hline Robert Chen & Alan Guberman & Ami Mankodi & Mark Sadler & Christina Wolfson \\
\hline Keith Chiappa & Gordon Gubitz & Wayne Martin & Dessa Sadovnick & John Wong \\
\hline Doug Cochrane & Abhijit Guha & Warren P. Mason & Ramesh Sahjpaul & Jerome Yager \\
\hline Fred Colbourne & Walter Hader & Eric Massicotte & Harvey B. Sarnat & Frank Yatsu \\
\hline Fiona Costello & Lorie Hamiwka & Charles Maxner & Robert Schmidt & G. Bryan Young* \\
\hline Stuart Coupland & Robert Hammond & Joann McIlwrick & Shashi Seshia & Eugene Yu \\
\hline Sultan Darvesh & Chunhai Hao & Martin McKeown & Keith Sharkey & Liang Zhang \\
\hline Alicia Debernardo & Alan Hill & Joseph Megyesi & M. Sharma & Wendy Ziai \\
\hline Marc Del Bigio & Michael Hill & Vivek Mehta & James Sharpe & \\
\hline Bart Demaerschalk & Douglas Hobson & Michel Melanson & Michael Shevell* & \\
\hline Andrew Demchuk & David Hogan & Ivar Mendez & Ashfaq Shuaib & \\
\hline Richard Desbiens* & Renn Holness & Tilak Mendis & Zaeem Siddiqi & \\
\hline Jeffrey Donat & Donna Holton & Jean Michaud & Sidorov & \\
\hline
\end{tabular}

* Editorial Board 